\title{
Empirical typology of bipolar I mood episodes*
}

David A. Solomon, Andrew C. Leon, Jean Endicott, William H. Coryell, Chunshan Li, Jess G. Fiedorowicz and Martin B. Keller

\section{Background}

Much remains unknown about the phenomenology of bipolar I disorder.

\section{Aims \\ To determine the type of bipolar I mood episodes that occur over time, and their relative frequency.}

\section{Method}

A total of 219 individuals with Research Diagnostic Criteria bipolar I disorder were prospectively followed for up to 25 years (median 20 years). Psychopathology was assessed with the Longitudinal Interval Follow-up Evaluation.

\section{Results}

Overall, 1208 mood episodes were prospectively observed. The episodes were empirically classified as follows: major depression, 30.9\% ( $n=373)$; minor depression, 13.0\% $(n=157)$; mania, 20.4\% $(n=246)$; hypomania, $10.4 \%(n=126)$; cycling, $17.3 \%(n=210)$; cycling plus mixed state, $7.8 \%$ $(n=94) ;$ and mixed, $0.2 \%(n=2)$.

\section{conclusions}

Cycling episodes constituted 25\% of all episodes. Work groups revising ICD-10 and DSM-IV should add a category for bipolar I cycling episode.

\section{Declaration of interest}

D.A.S. has served as investigator for research funded by the US National Institute of Mental Health (NIMH), the US National
Institute of Neurological Disorders and Stroke, Janssen Pharmaceutica, Wyeth-Ayerst Laboratories, and Merck; as consultant to Solvay Pharmaceuticals, Shire and Novartis; and on the lecture bureaux of AstraZeneca, Pfizer, GlaxoSmithKline, and Shire. A.C.L. has served as investigator for research funded by NIMH and the US National Institute of Drug Abuse, served on data safety monitoring boards for AstraZeneca, Dainippon Sumitomo Phrama (America), and Pfizer; and as consultant to the U.S. Food and Drug Administration, $\mathrm{NIMH}$, Cyberonics, and MedAvante (equity). J.E. has been an investigator for research funded by four of the US National Institutes of Health and the New York State Department of Mental Health, received research support from Abbott, Bristol-Meyers Squibb, Cyberonics, Interneuron, Merck, Parke-Davis, Pfizer, Upjohn, and Wyeth-Ayerst, and served as consultant/advisory board member for Abbott, AstraZeneca, Berlex, Bristol-Meyers Squibb, Cyberonics, Eli Lilly, Glaxosmithkline, Novartis, Otsuka, Janssen, Ovation, Pfizer, Sanofi-Synthelabo, and Wyeth-Ayerst. M.B.K. has served as consultant or received honoraria from Abbott, Cenerex, Cephalon, Cypress Bioscience, Cyberonics, Forest Laboratories, Janssen, JDS, Medtronic, Organon, Novartis, Pfizer, Roche, Solvay, and Wyeth Pharmaceuticals; received research support from Pfizer; and served on advisory boards for Abbott Laboratories, Bristol-Myers Squibb, Cenerex, Cyberonics, Cypress Bioscience, Forest Laboratories, Janssen, Novartis, Organon, and Pfizer.
One basic aspect of bipolar I disorder that deserves more study is the typology of the illness, meaning the type of different mood episodes that occur over time and their relative frequency. This issue is important because it has a direct impact on diagnosis, treatment and prognosis. In addition, studying the phenotypes of bipolar I disorder can only help ongoing efforts to specify its genetic aetiology and pathophysiology. ${ }^{1}$ The analyses presented below address the typology of bipolar I disorder, using data from the ongoing US National Institute of Mental Health Collaborative Program on the Psychobiology of Depression - Clinical Studies (Collaborative Depression Study), which began collecting prospective follow-up data on people with bipolar I disorder in 1978. ${ }^{2}$ The Collaborative Depression Study is in a unique position to determine the type and frequency of mood episodes that occur over time, owing to the combination of methodological strengths featured in the study, including direct interviews with participants, standardised diagnostic and follow-up instruments, frequent follow-up assessments, and up to 25 years of prospective follow-up. The importance of the length of follow-up cannot be overstated, as it allowed the investigators to better assess individuals with multiple, long mood episodes and multiple, long intervals of euthymia.

*Presented in part at the American Psychiatric Association, 161st Annual Meeting, Washington DC, 6 May 2008.

\section{Method}

\section{Participants}

From 1978 to 1981, the Collaborative Depression Study recruited patients receiving treatment for mood episodes at US academic medical centres in Boston, Chicago, Iowa City, New York, or St Louis. Inclusion criteria included age of at least 17 years, IQ greater than 70, ability to speak English, White ethnicity (genetic hypotheses were tested), knowledge of one's biological parents, and no signs of a mood disorder secondary to a general medical condition. The study was approved by the institutional review board at each study site, and participants provided written informed consent after receiving a complete description of the study.

A total of 955 patients entered the Collaborative Depression Study, all of whom met Research Diagnostic Criteria ${ }^{3}$ for a major mood episode at the time of enrollment. Included were 219 patients who (a) were diagnosed at study intake or during prospective follow-up with either bipolar I disorder or schizoaffective disorder, mainly affective subtype, (b) recovered from the mood episode present at study intake, and (c) eventually experienced at least one recurrent mood episode. These 219 individuals are the focus of the analyses presented below. (Research Diagnostic Criteria for bipolar I disorder are identical to the ICD-10 $0^{4}$ and DSM-IV ${ }^{5}$ criteria. Research Diagnostic Criteria $^{3}$ for schizoaffective disorder, mainly affective subtype, are very similar to the ICD- $10^{4}$ criteria and $\mathrm{DSM}-\mathrm{IV}^{5}$ criteria for bipolar I disorder. The inclusion of patients with 
schizoaffective disorder is consistent with the methods of other longitudinal studies of bipolar I disorder. ${ }^{6-8}$ Throughout the remainder of the paper, except where otherwise noted, the term 'bipolar I disorder' refers to individuals diagnosed with either bipolar I disorder or schizoaffective disorder, mainly affective subtype, according to Research Diagnostic (Criteria. $\left.{ }^{3}\right)$

\section{Initial diagnoses}

Of the 219 participants: 156 (71\%) were diagnosed at study intake with bipolar I disorder; $25(11 \%)$ were diagnosed at study intake with unipolar major depressive disorder but subsequently experienced at least one episode of mania during prospective follow-up; $14(6 \%)$ were diagnosed at study intake with bipolar II disorder but subsequently experienced at least one episode of mania during prospective follow-up; and 24 $(11 \%)$ were diagnosed at study intake with schizoaffective disorder, mainly affective subtype. The sample included five (2\%) individuals with unipolar mania. ${ }^{9}$

\section{Assessment instruments}

Raters interviewed participants at study intake about their current and past psychiatric history using the Schedule for Affective Disorders and Schizophrenia, ${ }^{10}$ reviewed medical records, and interviewed other informants whenever feasible. Diagnoses were then made according to Research Diagnostic Criteria. ${ }^{3}$

After study intake, raters assessed psychopathology through direct interviews conducted every 6 months for the first 5 years of the study and annually thereafter, using variations of the Longitudinal Interval Follow-up Evaluation. ${ }^{11}$ This semistructured instrument measured several variables, including severity of psychopathology. At each assessment, the interviewer rated the level of psychopathology for each week of the study, starting from the time of the last interview. To accomplish this, the rater first identified chronological anchor points such as holidays to assist the participant in remembering those times when significant clinical improvement or deterioration occurred. Whenever possible, corroborative data were obtained from medical records.

Raters received rigorous training before they were certified to conduct interviews. As a result, interrater reliability for the Longitudinal Interval Follow-up Evaluation is excellent, with high intraclass correlation coefficients (ICC) for rating changes in symptoms $\quad(\mathrm{ICC}=0.92)$, recovery from mood episodes $(\mathrm{ICC}=0.95)$, and reappearance of symptoms $(\mathrm{ICC}=0.88) .{ }^{11}$ Additionally, test-retest reliability is very good, with ICCs ranging from 0.85 to $0.93 .^{12}$

\section{Procedures}

Participants were followed prospectively for up to 25 years. The intake mood episode, described elsewhere, ${ }^{13}$ was not included in the analyses because it was not entirely prospective; individuals were enrolled into the Collaborative Depression Study after onset of the intake mood episode. All mood episodes described below commenced after participants had recovered from the mood episode present at study intake.

Consistent with Research Diagnostic Criteria, ${ }^{3}$ recovery from a mood episode was defined as at least 8 consecutive weeks with either no symptoms of major depression, minor depression, mania and hypomania, or only one or two symptoms of a mild degree; and no impairment of functioning. Recurrence or onset of a new mood episode was defined as the reappearance of major depression at full criteria for at least 2 consecutive weeks, mania at full criteria for at least 1 week, minor depression at the definite level for at least 2 consecutive weeks, or hypomania at the definite level for at least 1 week. Recurrence of a mood episode was considered to have occurred only after the individual had first recovered from the preceding mood episode.

\section{Types of mood episodes}

For the purposes of the present study, an empirical typology consisting of eight different categories was used to classify each observed mood episode, beginning with the categories of major depression, minor depression, mania, hypomania, and mixed episode. Minor depression was defined as at least 2 weeks of depressed mood accompanied by two or more other symptoms, without psychosis or the full depressive syndrome that characterises major depression. A mixed episode was defined as major depression or minor depression concurrent with mania or hypomania, throughout the entire episode (from onset of the episode to its end), with at least one major pole (mania or major depression) present at some point during the episode.

In addition, the classification system used in the present study included cycling mood episodes, because of their prevalence in this study, and their prevalence and prognostic significance in previous studies, ${ }^{13-21}$ including the work of Emile Kraepelin. ${ }^{22: \text { p.133 }}$ We empirically defined three categories of cycling mood episodes. Major cycling was defined as alternating periods of depression (major depression or minor depression) and mood elevation (mania or hypomania), immediately contiguous with each other or separated by fewer than 8 consecutive weeks of euthymia. In addition, at least one major pole (major depression or mania) was present at some point during the episode. Mixed major cycling was an episode of major cycling that at some point also included a mixed state, defined as a period of time with concurrent depression and mood elevation. The mixed state was immediately contiguous with the alternating periods of pure depression and mood elevation, or separated from them by fewer than 8 consecutive weeks of euthymia. (Mixed 'states' were distinguished from and not synonymous with the mixed 'episodes' defined above. A 'mixed state' referred to concurrent depression and mood elevation that occurred only during the course of a mixed major cycling episode. By contrast, a 'mixed episode' was a mood episode in which depression and mood elevation were concurrent throughout the entire episode.) Minor cycling was defined as alternating periods of hypomania and minor depression, immediately contiguous with each other or separated by fewer than 8 consecutive weeks of euthymia.

\section{Treatment}

The Collaborative Depression Study is an observational study in that treatment is not assigned by design and not controlled by anyone connected with the study. In fact, participants are not required to receive treatment.

In an observational study, the causal relationship between intensity of treatment and level of psychopathology is not known. For example, some participants are asymptomatic because they receive high levels of treatment, whereas others receive high levels of treatment because their symptoms are unremitting.

Over time, the intensity of treatment varied within participants as well as between participants. The type and dose of all prescribed somatic treatment were collected with the Longitudinal Interval Follow-up Evaluation ${ }^{11}$ and corroborated with available medical records. The results describe the mood stabilisers and antidepressants that participants received during follow-up. 


\begin{tabular}{|c|c|c|c|c|}
\hline Characteristic & $\begin{array}{l}\text { All participants } \\
\qquad(n=219)\end{array}$ & $\begin{array}{l}\text { Participants followed } \\
20 \text { years or more } \\
(n=122)\end{array}$ & $\begin{array}{l}\text { Participants followed } \\
\text { fewer than } 20 \text { years } \\
\qquad(n=97)\end{array}$ & Statistical test ${ }^{a}$ \\
\hline Age, years: mean (s.d.) & $37(13)$ & $34(9)$ & $41(16)$ & $\begin{aligned} t=3.87, & \text { d.f. }=147.50, \\
& P<0.001\end{aligned}$ \\
\hline \multicolumn{5}{|l|}{ Gender, $n$ (\%) } \\
\hline Male & $97(44)$ & $45(37)$ & $52(54)$ & \multirow{2}{*}{$\begin{array}{c}\chi^{2}=6.13, \text { d.f. }=1 \\
P=0.01\end{array}$} \\
\hline Female & $122(56)$ & $77(63)$ & $45(46)$ & \\
\hline \multicolumn{5}{|l|}{ Polarity of mood state at study intake, $n$ (\%) } \\
\hline Mania & $142(65)$ & $79(65)$ & $63(65)$ & \multirow{3}{*}{$\begin{array}{c}\chi^{2}=1.90, \text { d.f. }=2 \\
P=0.39\end{array}$} \\
\hline Major depression & $62(28)$ & $37(30)$ & $25(26)$ & \\
\hline Mixed & $15(7)$ & $6(5)$ & $9(9)$ & \\
\hline \multicolumn{5}{|l|}{ Psychosis, $n(\%)$} \\
\hline Present & $121(55)$ & $66(54)$ & $55(57)$ & \multirow{2}{*}{$\begin{array}{c}\chi^{2}=0.15, \text { d.f. }=1 \\
P=0.70\end{array}$} \\
\hline Absent & $98(45)$ & $56(46)$ & $42(43)$ & \\
\hline Global Assessment Scale score: ${ }^{c}$ mean (s.d.) & $32(11)$ & $33(10)$ & $32(11)$ & $\begin{array}{c}t=-0.94, \text { d.f. }=217 \\
P=0.35\end{array}$ \\
\hline $\begin{array}{l}\text { Age at onset of first lifetime mood episode, } \\
\text { years: }{ }^{d} \text { mean (s.d.) }\end{array}$ & $24(10)$ & $23(8.5)$ & $26(11)$ & $\begin{array}{c}t=2.87, \text { d.f. }=76.01, \mathrm{~b} \\
P<0.01\end{array}$ \\
\hline \multicolumn{5}{|c|}{ Number of mood episodes prior to intake episode, ${ }^{e} n(\%)$} \\
\hline 0 & $27(12)$ & $13(11)$ & $14(14)$ & \multirow{4}{*}{$\begin{array}{c}\text { Mann-Whitney } Z=-0.22 \\
\qquad P=0.83\end{array}$} \\
\hline 1 & $20(9)$ & $14(11)$ & $6(6)$ & \\
\hline 2 & $26(12)$ & $15(12)$ & $11(11)$ & \\
\hline 3 or more & $146(67)$ & $80(66)$ & $66(68)$ & \\
\hline \multicolumn{5}{|c|}{$\begin{array}{l}\text { a. Statistical tests compared participants followed } 20 \text { years or more }(n=122) \text { with those followed fewer than } 20 \text { years }(n=97) \text {. } \\
\text { b. Degrees of freedom were adjusted for unequal variances. } \\
\text { c. The range for the Global Assessment Scale } 23 \text { is } 1-100 \text {, and higher numbers indicate less psychopathology and better psychosocial functioning. } \\
\text { d. Major depression, minor depression, mania or hypomania. } \\
\text { e. Percentages do not sum to } 100 \text { because of rounding. }\end{array}$} \\
\hline
\end{tabular}

\section{Results}

\section{Participants and length of follow-up}

Table 1 displays the sociodemographic and clinical characteristics at study intake (online Table DS1 shows the complete results). The mean (s.d.) length of follow-up was 17.3 (7.9) years and the median was 20 years. Of the 219 participants, 196 (90\%) were followed for at least 5 years, $169(77 \%)$ for at least 10 years, 144 (66\%) for at least 15 years, and $122(56 \%)$ were followed for at least 20 years. Compared with participants followed for fewer than 20 years, those followed for 20 or more years were significantly younger both at study intake and at onset of bipolar I disorder (as expected); they were also significantly more likely to be female.

\section{Number of mood episodes}

A total of 1208 recurrent mood episodes were prospectively observed. The median number of mood episodes observed per participant was 4 (range 1-21). The mean (s.d.) number of episodes per participant was 5.5 (4.6). The mean (s.d.) number of observed episodes per participant per year of follow-up was $0.4(0.3)$

\section{Typology}

Table 2 shows the frequency of each type of mood episode observed during follow-up. Major depression was most common.

Episodes consisting of a single pole of psychopathology (major depression, minor depression, mania, or hypomania) comprised $902(75 \%)$ of the mood episodes. Of these 902 episodes, 578 occurred in female participants $(n=122)$, and consisted of 336 (58\%) depressive episodes (major or minor depression) and 242 (42\%) mood-elevated episodes (mania or hypomania). The 324 remaining episodes that occurred in male participants $(n=97)$ and consisted of $194(60 \%)$ depressive episodes and 130 (40\%) mood-elevated episodes. A mixed-effects logistic regression model (which accounted for the correlation among multiple, withinparticipant mood episodes) showed that gender was not significantly associated with the polarity of episode (depressive $v$. mood elevated; odds ratio $(\mathrm{OR})=0.76$, 95\% CI 0.37-1.58, $Z=-0.73, P=0.46$ ).

Mixed states occurred as part of mixed major cycling episodes, which comprised $8 \%(n=94)$ of the mood episodes. In addition, only two mixed episodes (major depression or minor depression concurrent with mania or hypomania throughout the entire episode, with at least one major pole) were observed.

There were 151 mood episodes prospectively observed in the subgroup with a diagnosis of schizoaffective disorder, mainly affective subtype, and 1057 observed in the subgroup with bipolar I disorder. The typologies of the two subgroups were similar.

\section{Cycling mood episodes}

Table 3 shows the sequence of component mood states for 296 cycling episodes (major cycling, mixed major cycling, or minor cycling). In the 153 cycling episodes that began with depression (either major depression or minor depression), the depressive state was followed by an immediate switch to mood elevation or a mixed state in $64 \%$ of the episodes. In the 143 cycling episodes that began with mood elevation (either mania or hypomania), the elevated state was followed by an immediate switch to depression or a mixed state in $56 \%$ of the episodes.

\section{Change of mood episodes over time}

Online Table DS2 displays the typology of the mood episodes that occurred from 1978 to 1991 and from 1992 to 2006. A mixed-effects logistic regression model showed that mood 


\begin{tabular}{|c|c|c|c|c|}
\hline \multirow[b]{2}{*}{ Type of mood episode } & \multirow{2}{*}{$\begin{array}{c}\text { Episodes, } \\
n(\%)\end{array}$} & \multirow{2}{*}{$\begin{array}{l}\text { Participants who } \\
\text { experienced the } \\
\text { episode type, }{ }^{\mathrm{b}} n\end{array}$} & \multicolumn{2}{|c|}{$\begin{array}{l}\text { Number of episodes among participants who } \\
\text { experienced the episode type }\end{array}$} \\
\hline & & & Mean (s.d.) & Range \\
\hline Major depression & $373(30.9)$ & 130 & $2.9(2.5)$ & $1-11$ \\
\hline Minor depression & $157(13.0)$ & 80 & $2.0(1.3)$ & $1-7$ \\
\hline Mania & $246(20.4)$ & 98 & $2.5(2.3)$ & $1-16$ \\
\hline Hypomania & $126(10.4)$ & 77 & $1.6(1.1)$ & $1-6$ \\
\hline Major cycling & $182(15.1)$ & 97 & $1.9(1.5)$ & $1-10$ \\
\hline Mixed major cycling & $94(7.8)$ & 63 & $1.5(1.1)$ & $1-8$ \\
\hline Minor cycling & $28(2.3)$ & 22 & $1.3(0.6)$ & $1-3$ \\
\hline Mixed & $2(0.2)$ & 2 & $1.0(0.0)$ & $1-1$ \\
\hline Total & $1208(100)$ & & & \\
\hline
\end{tabular}

episodes from 1978 to 1991 were $37 \%$ less likely to be an episode of major depression, compared with mood episodes that occurred from 1992 to $2006(\mathrm{OR}=0.63,95 \%$ CI $0.44-0.90, Z=-2.55$, $P=0.01)$.

\section{Treatment}

We examined the somatic therapy received during mood episodes. Of the 1208 mood episodes, 85\% $(n=1026)$ were treated with a mood stabiliser and/or an antidepressant for at least 1 week during prospective follow-up.

Online Table DS3 displays in greater detail the treatment that occurred. Of the 843 mood episodes selected for analysis, many were not treated with a mood stabiliser, including $40 \%$ (131/326) of the major depressive episodes, 39\% (57/145) of the minor depressive episodes, $12 \%$ (30/246) of the manic episodes, and $24 \%(30 / 126)$ of the hypomanic episodes. Of the depressive (major or minor) episodes selected for analysis, 28\% (134/471) were treated with an antidepressant in the absence of a mood stabiliser.

\section{Discussion}

\section{Number of mood episodes}

The number of observed mood episodes $(n=1208)$ was conditioned by the method of the study, which set a relatively high threshold for recovery from a mood episode. Furthermore, alternating syndromes of depression and mood elevation with no intervening period of recovery were counted as a single cycling episode, rather than as multiple, separate mood episodes. Participants were not recruited from bipolar disorder specialty clinics, which may draw upon patients that are more resistant to maintenance treatment and more vulnerable to recurrences.

\section{Cycling and implications for nosology}

The term 'cycling' was originally used in the literature to indicate a switch from a mood syndrome of one polarity to a syndrome of the opposite polarity (e.g. major depression to mania), in the absence of an intervening period of recovery. ${ }^{14,24} \mathrm{ICD}-10^{4}$ makes no reference to this phenomenon and does not use the term cycling. DSM-IV ${ }^{5}$ does not recognise this phenomenon either, but it does include the specifier 'rapid cycling', which represents something altogether different: rapid cycling is applied when four or more mood episodes occur in a 12 -month period.

In the absence of a category for mood episodes that consist of alternating syndromes of depression and mood elevation with no intervening period of recovery, the current convention is that each alternating mood syndrome is simply classified as a separate mood episode. This occurs regardless of how little time, if any, elapses between the end of one syndrome and the onset of the next. A recent review paper, however, takes the position that cycling or switching is an important phenomenon that should be monitored in clinical trials, ${ }^{25}$ and for good reason. Prior research has found that cycling episodes occur frequently, ${ }^{15,18,19,22: \text { p.133 }}$ consistent with the present study, which found that cycling episodes comprised $25 \%$ of the observed mood episodes. In addition, cycling episodes are associated with poorer outcomes compared

\begin{tabular}{|c|c|c|}
\hline Possible outcomes $^{b}$ & $\begin{array}{l}\text { Sequence when initial mood state } \\
\text { was depression }(n=153), n(\%)\end{array}$ & $\begin{array}{l}\text { Sequence when initial mood state was } \\
\text { mood elevation }(n=143), n(\%)\end{array}$ \\
\hline Change to mood elevation & $69(45.1)$ & - \\
\hline Change to depression & - & $62(43.4)$ \\
\hline Change to mixed state & $29(19.0)$ & $18(12.6)$ \\
\hline Change to euthymia followed by mood elevation & $33(21.6)$ & $10(7.0)$ \\
\hline Change to euthymia followed by depression & $21(13.7)$ & $53(37.1)$ \\
\hline Change to euthymia followed by mixed state & $1(0.7)$ & 0 \\
\hline \multicolumn{3}{|c|}{$\begin{array}{l}\text { a. This table displays the sequence of mood states for the } 296 \text { cycling mood episodes that began with either depression (major depression or minor depression; } n=153 \text { ) or mood } \\
\text { elevation (mania or hypomania; } n=143 \text { ). The } 296 \text { cycling episodes consisted of } 182 \text { major cycling episodes, } 86 \text { mixed major cycling episodes, and } 28 \text { minor cycling episodes. The table } \\
\text { does not include results for the eight mixed major cycling episodes that began with a mixed state. } \\
\text { b. Change to mood elevation refers to a switch to either mania or hypomania. Change to depression refers to a switch to either major depression or minor depression. Change to } \\
\text { mixed state refers to a switch to concurrent depression plus mood elevation. }\end{array}$} \\
\hline
\end{tabular}


with episodes of pure major depression or pure mania, including significantly more hospital admissions, ${ }^{14}$ a significantly longer time to recovery from mood episodes, ${ }^{13,14,16,26}$ a significantly shorter time to recurrence, ${ }^{16}$ and significantly worse psychosocial functioning. ${ }^{14,17}$ Work groups revising ICD-10 4 and DSM-IV ${ }^{5}$ should formally recognise cycling episodes, which hopefully will lead to further study of the phenomenon, as there may be specific pathophysiological processes that cause a cycling mood episode ${ }^{27}$ cycling may be associated with certain aspects of bipolar I disorder such as suicide, and it may be possible to develop specific treatments for cycling mood episodes.

\section{Minor depression and implications for nosology}

Although ICD- $10^{4}$ recognises episodes of bipolar I minor depression, DSM-IV ${ }^{5}$ does not. Yet we found that minor depression comprised $13 \%$ of all observed mood episodes, consistent with other studies that have described bipolar I minor depression. ${ }^{15,18,28}$ The lack of recognition of bipolar I minor depression in DSM-IV ${ }^{5}$ is an oversight that should be corrected in DSM-V.

\section{Typology and earlier studies}

To provide some context for the typology presented above, it is useful to compare the results with previous studies. Kraepelin ${ }^{22}$ reported that among a series of 899 cases, ' $48.9 \%$ presented states of depression only, $16.6 \%$ manic attacks only, and $34.5 \%$ a combination of manic and depressive morbid phenomena, sometimes one after the other sometimes alongside each other' (p. 133). By comparison, the results above (Table 2) were such that of the 1208 mood episodes observed, $43.9 \%(n=530)$ were depressive episodes, $30.8 \%(n=372)$ were mood-elevated episodes, and $25.3 \%(n=306)$ were cycling or mixed episodes. The two sets of results were comparable, particularly with regard to depression, despite a difference of nearly 100 years separating the two studies.

In comparing these percentages, it should be noted that Kraepelin's $^{22}$ melancholia gravis and simplex are not entirely synonymous with Research Diagnostic Criteria major and minor depression (pp. 75-85). Melancholia gravis is comparable to major depression with psychotic features, and melancholia simplex overlaps with major depression without psychotic features. However, major depression without psychotic features includes episodes with less severe or intense psychopathology that do not rise to the level of melancholia simplex, and the category of minor depression did not merit attention in Kraepelin's list of depressive states.

More recently, Angst ${ }^{15}$ observed 1164 mood episodes from 1959 to 1975 in people with bipolar disorder prospectively assessed every 5 years. He categorised mood episodes as major (major depression or mania) if they required hospital admission, and as minor (minor depression or hypomania) if they did not. Major depression constituted $24 \%$ of the episodes, minor depression $28 \%$, mania $17 \%$, hypomania $5 \%$, and mixed or cycling episodes $27 \%$. Although these results were in some respects quite similar to those of the present study, the proportion of episodes classified as minor depression was $13 \%$ in the present study and 28\% in Angst's study. This difference is not surprising, given the different definitions of minor depression that were used in the two studies.

\section{Mood episodes and mood symptoms}

The results regarding the typology of mood episodes complement findings from a previous Collaborative Depression Study report ${ }^{29}$ that focused on weekly symptoms. In the present study, episodes of depression constituted nearly $44 \%$ of the observed episodes and were more frequent than other types of episodes. In the prior study, ${ }^{29}$ the most prevalent psychopathology was depression, which accounted for approximately $64 \%$ of all weeks that individuals were symptomatic. These different percentages highlight the relationship between episode frequency and length. In addition, it is important to bear in mind that in the prior study, a shift in symptom polarity (from depression to mood elevation or vice versa) occurred a mean (s.d.) of 3.5 (7.4) times per year. Thus, some of the 'depressed' weeks observed in the prior study were part of the cycling mood episodes observed in the present study, rather than the major or minor depressive episodes.

\section{Mixed states and episodes}

Mixed states of concurrent depression and mood elevation occurred as part of mixed major cycling episodes, which comprised $8 \%(n=94)$ of the mood episodes. In addition, there were only two mixed episodes (depression concurrent with mood elevation throughout the entire episode, from onset of the episode to its end). Relative to some prior studies, mixed states in our study were scarce, and mixed episodes were exceedingly rare. These results are clearly a function of how mixed states and mixed episodes were defined in the present study. A review of 17 previous studies found that among all mood episodes, the prevalence of mixed mania or hypomania ranged from 5 to $70 \% .{ }^{30}$ One study found that clinically significant (two or more) depressive symptoms occurred in $94 \%$ of patients meeting criteria for mania or hypomania, and clinically significant manic symptoms occurred in $70 \%$ of patients meeting criteria for major depression. $^{31}$

Some previous studies may have used the term 'mixed' to refer to the same phenomenon - alternating periods of depression and mood elevation with no intervening period of recovery - which the present study designated as 'cycling'. We prefer this term because its use is well established and extends as far back as 1845. ${ }^{14,24}$ This issue may contribute to the ongoing controversy concerning the diagnosis of mixed episodes. ${ }^{32}$

\section{Limitations}

One limitation is that the proposed construct of bipolar I cycling episode requires a prospectively designed psychometric evaluation, in which rigorous structured diagnostic interviews are regularly administered, and the interviews provide the information necessary to ascertain whether or not criteria for a wide range of diagnoses are fulfilled. Another limitation is the absence of participants with bipolar II disorder. In addition, participants were recruited at varying points in their course of illness, with some enrolled close to onset of bipolar I disorder, and others further removed from onset. Also, the time that elapsed between assessments (initially 6 months and subsequently 12 months) may have introduced recall bias and limited the accuracy of the results.

The sample was quite ill at study intake, such that $89 \%$ of the participants were in-patients of academic medical centres and $55 \%$ had psychosis, which may limit the generalisability of the findings. Yet another limitation is that treatment was not controlled and may not have been optimal. The present longitudinal study is also limited by attrition, which could have biased some of the findings.

Finally, additional work is required to examine the course of illness across each of the eight mood episode types. This includes examining length of mood episodes and the rate of recurrence. 
David A. Solomon, MD, Department of Psychiatry and Human Behavior, The Warren Alpert Medical School of Brown University, Providence, Rhode Island, and UpToDate Inc., Waltham, Massachusetts; Andrew C. Leon, PhD, Department of Psychiatry, Weill Cornell Medical College, New York; Jean Endicott, PhD, New York State Psychiatric Institute, New York; William H. Coryell, MD, Department of Psychiatry, Roy J. and Lucille A. Carver College of Medicine, University of lowa Hospitals and Clinics, Iowa City, lowa; Chunshan Li, MA, Department of Psychiatry, Weill Cornell Medical College, New York; Jess G. Fiedorowicz, MD, MS, Department of Psychiatry, Roy J. and Lucille A. Carver College of Medicine, University of lowa Hospitals and Clinics, lowa City, lowa; Martin B. Keller, MD, Department of Psychiatry and Human Behavior, The Warren Alpert Medical School of Brown University, Providence, Rhode Island, USA

Correspondence: David A. Solomon, MD, Mood Disorders Program, Department of Psychiatry, Rhode Island Hospital, 593 Eddy Street, Providence Rhode Island, 02903-4970, USA. Email: DASolomon@Lifespan.org

First received 23 Nov 2008, final revision 25 Jul 2009, accepted 2 Aug 2009

\section{Funding}

Funding for this study was provided by US National Institute of Mental Health grant MH25478-29.

\section{Acknowledgements}

This manuscript has been reviewed by the Publication committee of the Collaborativ Depression Study and has its endorsement. The data for this manuscript came from the National Institute of Mental Health (NIMH) Collaborative Program on the Psychobiology of Depression - Clinical Studies. The Collaborative Program was initiated in 1975 to investigate nosologic, genetic, family, prognostic, and psychosocial issues of mood disorders, and is an ongoing, long-term multidisciplinary investigation of the course of mood and related affective disorders. The original principal and co-principal investigators were from five academic centers and included: Gerald Klerman, MD (deceased; Co-Chairperson); Martin Keller, MD; Robert Shapiro, MD (deceased), Massachusetts General Hospital, Harvard Medical School; Eli Robbins, MD (deceased), Paula Clayton, MD, Theodore Reich, MD (deceased), Amos Wellner, MD (deceased), Washington University Medical School; Jean Endicott, PhD, Robert Spitzer, MD, (Columbia University); Nancy Andreasen, MD, PhD, William Coryell, MD, George Winokur, MD (deceased), University of Iowa; and Jan Fawcett, MD, William scheftner, MD, Rush-Presbyterian-St. Luke's Medical Center. The NIMH Clinical $\mathrm{MD}$, William Scheftner, MD, Rush-Presbyterian-St. Luke's Medical Center. The
Research Branch was an active collaborator in the origin and development of the Collaborative Program with Martin M. Katz, Branch Chief as the Co-Chairperson and Rober Hirschfeld as the Program Coordinator. Other past collaborators include J. Croughan, MD, M.T. Shea, PhD, R. Gibbons, PhD, M.A. Young, PhD, and D.C. Clark, PhD.

This study was conducted with the current participation of the following investigators: M.B.K. (Chairperson), W.H.C. (Co-Chairperson), D.A.S., W. Scheftner, MD (Chicago, Illinois), J.E., A.C.L. and J. Loth, MSW (New York), and J. Rice, PhD (St. Louis, Missouri).

\section{References}

1 Craddock N, Sklar P. Genetics of bipolar disorder: successful start to a long journey. Trends Genet 2009; 25: 99-105.

2 Katz MM, Secunda SK, Hirschfeld RMA, Koslow SH. NIMH Clinical Research Branch Collaborative Program on the Psychobiology of Depression. Arch Gen Psychiatry 1979; 36: 765-71.

3 Spitzer RL, Endicott J, Robins E. Research Diagnostic Criteria: rationale and reliability. Arch Gen Psychiatry 1978; 35: 773-82.

4 World Health Organization. International Statistical Classification of Diseases and Related Health Problems, 10th Revision, Version for 2007. WHO, 2006 (http://www.who.int/classifications/apps/icd/icd10online/gf30.htm).

5 American Psychiatric Association. Diagnostic and Statistical Manual of Mental Disorders (4th edn) (DSM-IV). APA, 1994.

6 Angst J, Gamma A, Sellaro R, Lavori PW, Zhang H. Recurrence of bipolar disorders and major depression: a life-long perspective. Eur Arch Psychiatry Clin Neurosci 2003; 253: 236-40.

7 Sachs GS, Thase ME, Otto MW, Bauer M, Miklowitz D, Wisniewski SR, et al. Rationale, design, and methods of the Systematic Treatment Enhancement Program for Bipolar Disorder (STEP-BD). Biol Psychiatry 2003; 53: 1028-42.

8 Nolen WA, Luckenbaugh DA, Altshuler LL, Suppes T, McElroy SL, Frye MA, et al. Correlates of 1-year prospective outcome in bipolar disorder: results from the Stanley Foundation Bipolar Network. Am J Psychiatry 2004; 161: 1447-54.
9 Solomon DA, Leon AC, Endicott J, Coryell WH, Mueller TI, Posternak MA, et al. Unipolar mania over the course of a 20-year follow-up study. Am J Psychiatry 2003; 160: 2049-51.

10 Endicott J, Spitzer RL. A diagnostic interview: the Schedule for Affective Disorders and Schizophrenia. Arch Gen Psychiatry 1978; 35: 837-44.

11 Keller MB, Lavori PW, Friedman B, Nielsen E, Endicott J, McDonald-Scott P, et al. The longitudinal interval follow-up evaluation: a comprehensive method for assessing outcomes in prospective longitudinal studies. Arch Gen Psychiatry 1987; 44: 540-8.

12 Warshaw MG, Keller MB, Stout RL. Reliability and validity of the Longitudinal Interval Follow-up Evaluation for assessing outcome of anxiety disorders. I Psychiatr Res 1994; 28: 531-45.

13 Keller MB, Lavori PW, Coryell W, Andreasen NC, Endicott J, Clayton PJ, et al. Differential outcome of pure manic, mixed/cycling, and pure depressive episodes in patients with bipolar illness. JAMA 1986; 255: 3138-42.

14 Maj M, Pirozzi R, Magliano L, Bartoli L. The prognostic significance of 'switching' in patients with bipolar disorder: a 10-year prospective follow-up study. Am J Psychiatry 2002; 159: 1711-7.

15 Angst J. The course of affective disorders: II. Typology of bipolar manicdepressive illness. Arch Psychiat Nervenkr 1978; 226: 65-73.

16 Keller MB, Lavori PW, Coryell W, Endicott J, Mueller TI. Bipolar I: a five-year prospective follow-up. J Nerv Ment Dis 1993; 181: 238-45.

17 Turvey CL, Coryell WH, Solomon DA, Leon AC, Endicott J, Keller MB. Longterm prognosis of bipolar I disorder. Acta Psychiatr Scand 1999; 99: 110-9.

18 Kukopulos A, Reginaldi D, Laddomada P, Floris G, Serra G, Tondo L. Course of the manic-depressive cycle and changes caused by treatments. Pharmakopsychiatr Neuropsychopharmakol 1980; 13: 156-67.

19 Roy-Byrne P, Post RM, Unde TW, Porcu T, Davis D. The longitudinal course of recurrent affective illness: life chart data from research patients at the NIMH. Acta Psychiatr Scand 1985; 71 (suppl 317): 3-34

20 Cole AJ, Scott J, Ferrier IN, Eccleston D. Patterns of treatment resistance in bipolar affective disorder. Acta Psychiatr Scand 1993; 88: 121-3.

21 Post RM, Denicoff KD, Leverich GS, Altshuler LL, Frye MA, Suppes TM, et al. Morbidity in 258 bipolar outpatients followed for 1 year with daily prospective ratings on the NIMH Life Chart Method. J Clin Psychiatry 2003; 64: 680-90.

22 Kraepelin E. Manic-Depressive Insanity and Paranoia (trans RM Barclay, ed GM Robertson). E \& S Livingstone, 1921.

23 Endicott J, Spitzer RL, Fleiss JL, Cohen J. The Global Assessment Scale: a procedure for measuring overall severity of psychiatric disturbance. Arch Gen Psychiatry 1976; 33: 766-71.

24 Koukopoulos A, Sani G, Koukopoulos AE, Albert MJ, Girardi P, Tatarelli R Endogenous and exogenous cyclicity and temperament in bipolar disorder: review, new data and hypotheses. J Affect Disord 2006; 96: 165-75.

25 Martinez-Aran A, Vieta E, Chengappa KNR, Gershon S, Mullen J, Paulsson B. Reporting outcomes in clinical trials for bipolar disorder: a commentary and suggestions for change. Bipolar Disord 2008; 10: 566-79.

26 Solomon DA, Leon AC, Coryell WH, Endicott J, Li C, Fiedorowicz JG, et al. The longitudinal course of bipolar I mood episodes: duration of mood episodes. Arch Gen Psychiatry, in press.

27 Bunney Jr WE, Goodwin FK, Murphy DL, House KM, Gordon EK. The 'switch process' in manic-depressive illness. II. Relationship to catecholamines, REM sleep, and drugs. Arch Gen Psychiatry 1972; 27: 304-9.

28 Suppes T, Mintz J, McElroy SL, Altshuler LL, Kupka RW, Frye MA, et al. Mixed hypomania in 908 patients with bipolar disorder evaluated prospectively in the Stanley Foundation Bipolar Treatment Network: a sex specific study. Arch Gen Psychiatry 2005; 62: 1089-96.

29 Judd LL, Akiskal HS, Schettler PJ, Endicott J, Maser J, Solomon DA, et al. The long-term natural history of the weekly symptomatic status of bipolar I disorder. Arch Gen Psychiatry 2002; 59: 530-7.

30 McElroy SL, Keck Jr PE, Pope Jr HG, Hudson Jl, Faedda GL, Swann AC. Clinical and research implications of the diagnosis of dysphoric or mixed mania or hypomania. Am J Psychiatry 1992; 149: 1633-44.

31 Bauer MS, Simon GE, Ludman E, Unützer J. 'Bipolarity' in bipolar disorder: distribution of manic and depressive symptoms in a treated population. Br J Psychiatry 2005; 187: 87-8.

32 Ghaemi SN. All mixed up: on the absence of diagnostic guidelines for mixed states in the ISBD Diagnostic Guidelines Task Force Report. Bipolar Disord 2008; 10: 129-30. 